\title{
Paradoxical role of an Egr transcription factor family member, Egr2/Krox20, in learning and memory
}

\author{
Roseline Poirier $^{1,2 *}$, Hélène Cheval ${ }^{1,2}$, Caroline Mailhes $^{3}$, Patrick Charnay ${ }^{3}$, Sabrina Davis ${ }^{1,2}$ \\ and Serge Laroche ${ }^{1,2}$
}

1. Laboratoire de Neurobiologie de l'Apprentissage, Univ Paris Sud, France

2. CNRS, UMR 8620 , France

3. INSERM, U784, Génétique Moléculaire du Développement, Ecole Normale Supérieure, France

Edited by: Carmen Sandi, Ecole Polytechnique Federale de Lausanne, Switzerland

Reviewed by: Carmen Sandi, Ecole Polytechnique Federale de Lausanne, Switzerland

Cesar Venero, Universidad Nacional de Educación a Distancia, Spain

It is well established that Egr1/zif268, a member of the Egr family of transcription factors, is critical for the consolidation of several forms of memories. Recently, the Egr3 family member has also been implicated in learning and memory. Because Egr family members encode closely related zinc-finger transcription factors sharing a highly homologous DNA binding domain that recognises the same DNA sequence, they may have related functions in brain. Another Egr family member expressed in brain, Egr2/Krox20 is known to be crucial for normal hindbrain development and has been implicated in several inherited peripheral neuropathies; however, due to Egr2-null mice perinatal lethality, its potential role in cognitive functions in the adult has not been yet explored. Here, we generated Egr2 conditional mutant mice allowing postnatal, forebrain-specific Cre-mediated Egr2 excision and tested homozygous, heterozygous and control littermates on a battery of behavioural tasks to evaluate motor capacity, exploratory behaviour, emotional reactivity and learning and memory performance in spatial and non-spatial tasks. Egr2-deficient mice had no sign of locomotor, exploratory or anxiety disturbances. Surprisingly, they also had no impairment in spatial learning and memory, taste aversion memory or fear memory using a trace conditioning paradigm. On the contrary, Egr2-deficient mice had improved performance in motor learning on a rotarod, and in object recognition memory. These results clearly do not extend the phenotypic consequences resulting from either Egr1 or Egr3 loss-of-function to Egr2. In contrast, they indicate that Egr family members may have different, and in certain circumstances antagonistic functions in the adult brain.

Keywords: transcription factor, Egr, Krox20, Zif268, learning, memory, conditional mutant mouse

\section{INTRODUCTION}

In brain, multiple inducible, nuclear transcription factors act as critical regulators of long-term, activity-dependent adaptive responses of neurons such as in processes of neuronal plasticity in response to synaptic activation and the formation of long-term memories for newly learned events. As in many aspects of cell function, the rapid activation of transcription factors in neurons is part of an early genomic response that constitutes a critical step in the molecular mechanisms required for persistent neuronal modification and the laying down of long-term memories. Amongst the activity regulated transcription factors, the immediate early growth response-1 gene Egr1 (also named Zif268, Krox24, NGFI-A and TIS8 or the avian homolog Zenk), a member of the Egr

*Correspondence: Roseline Poirier, Laboratoire de Neurobiologie de l'Apprentissage, de la Mémoire et de la Communication, UMR 8620, Université Paris-Sud, 91405 Orsay, France. Tel.: +33 (0)1 691549 85; Fax: +33 (0)1 69157726 .

e-mail: roseline.poirier@ u-psud.fr

Received: 13 Nov. 2007; paper pending published: 23 Nov. 2007; accepted: 30 Nov. 2007; Published online: 30 Dec. 2007

Full citation: Frontiers in Behavioral Neuroscience (2007) 1:6 doi: 10.3389/neuro.08/ 006.2007

Copyright (C) 2007 Poirier, Cheval, Mailhes, Charnay, Davis and Laroche. This is an openaccess article subject to an exclusive license agreement between the authors and the Frontiers Research Foundation, which permits unrestricted use, distribution, and reproduction in any medium, provided the original authors and source are credited. family of transcriptional regulators, is one of the best characterised for its role in neural plasticity and memory formation (Davis et al., 2003; Knapska and Kaczmarek, 2004; 0'Donovan et al., 1999 for reviews). Numerous studies over the past several years have shown that the expression of Egr1 is rapidly induced in defined brain structures after specific learning experiences or exposure to learning-associated events (e.g. Guzowski et al., 2001; Hall et al., 2001; Malkani and Rosen, 2000; Maviel et al., 2004; Okuno and Miyashita, 1996; Thomas et al., 2002). In dentate gyrus of the hippocampus, Egr1 is rapidly expressed after induction of long-term potentiation (LTP), an activity-dependent form of synaptic plasticity believed to play a crucial role in the formation of memories, and its regulated expression is closely linked to the persistence of LTP (Abraham et al., 1991; Abraham et al., 1993; Richardson et al., 1992; Worley et al., 1993). Further, studies in mutant mice have demonstrated that Egr1 inactivation prevents the maintenance of synaptic plasticity in the hippocampus and severely impairs the consolidation and reconsolidation of several types of long-term memories (Bozon et al., 2002; Bozon et al., 2003a; Bozon et al., 2003b; Jones et al., 2001). Consolidation or reconsolidation deficits have also been reported after injection of specific Egr1 antisense oligonucleotides in defined brain structures (Lee et al., 2004; Malkani et al., 2004).

Egr1 belongs to a family of four closely related genes that also includes Egr2 (Krox2O), Egr3 (Pilot) and Egr4 (NGFI-C). Although the role of Egr1 in learning and memory is well established, that of other members of the Egr family is less well documented. Recently however, Li et al., (2007) 
analysed the phenotype of Egr3 knock-out mice and found that Egr3 deficiency also results in learning and memory deficits. There are however important qualitative differences between the phenotype of Egr1 and Egr3 mutant mice. Whereas Egr1 inactivation results in deficits restricted to the stabilisation of hippocampal late-phase LTP and to long-term, but not short-term memory (Jones et al., 2001), the early phases of hippocampal LTP and short-term memory are compromised in Egr3-deficient mice (Li et al., 2007). Moreover, Egr3 mutant mice display increased sensitivity and responsiveness to stressful stimuli and novel environments (GallitanoMendel et al., 2007). Thus, although the four Egr family members encode closely related $\mathrm{Cys}_{2}-\mathrm{Hys}_{2}$ zinc-finger transcription factors, highly homologous (92\%) in the zinc-finger DNA binding domain (Beckmann and Wilce, 1997) and interacting with the same GC-rich consensus DNA motif, suggesting that the proteins may bind to cis-regulatory regions of at least a subset of the same target genes (Chavrier et al., 1990; Lemaire et al., 1990; Swirnoff and Milbrandt, 1995), comparison of the phenotypes of Egr1 and Egr3 mutant mice raises the possibility that Egr members may have at least in part diverging physiological functions in the adult brain.

In the experiments reported here, our aim was to examine whether Egr2 is also critically involved in learning and memory and to investigate whether Egr2 deficiency would result in behavioural deficits qualitatively similar to those found in Egr1 or Egr3 mutant mice. In general, Egr family members show a similar regional profile of basal expression in forebrain regions. Egr2 mRNA and protein have been detected in several areas of the neocortex, hippocampus, amygdala, olfactory bulb, striatum, cerebellum, diencephalic and brainstem structures, although its expression is generally weaker than that of Egr1 (reviewed in Beckmann and Wilce, 1997). There are however some differences in their tissue distribution. Egr2 expression is restricted to neurons in the central nervous system, with only glial cells of the peripheral system containing Egr2 (Herdegen et al., 1993). In contrast to Egr1 and Egr3, Egr2 protein has been detected in both the nucleus and cytoplasm of forebrain neurons (De et al., 2003; Mack et al., 1992). In the hippocampus, both Egr1 and Egr2 are highly expressed in CA1-3 pyramidal cells, with negligible basal levels in granule cells of the dentate gyrus (Herdegen et al., 1993; Mack et al., 1990; Yamagata et al., 1994). In cortex however, constitutive levels of Egr2 are highest in layers II and III but sparse in layers IV and VI, whereas Erg3 and Egr4 are highly expressed in layers II and IV (Beckmann and Wilce, 1997).

Relatively little is known about the functional role of Egr2 in the adult brain. In humans, mutations affecting Egr2 are found in patients diagnosed for inherited peripheral neuropathies, including congenital hypomyelinating neuropathy, Charcot-Marie-Tooth type 1 disease and Dejerine-Sottas syndrome (Bellone et al., 1999; Boerkoel et al., 2001; Pareyson et al., 2000; Timmerman et al., 1999; Warner et al., 1998; Yoshihara et al., 2001). The consequences of Egr2 inactivation were explored in conventional Egr2-null mutant mice and these studies revealed a prominent role of Egr2 in the regulation of peripheral nerve myelination (Topilko et al., 1994) as well as in hindbrain segmentation (Giudicelli et al., 2001; Schneider-Maunoury et al., 1993; Swiatek and Gridley, 1993) and endochondreal bone formation (Levi et al., 1996). At present, the suggestion that Egr2 may have a biological function in the adult brain has been limited to examination of its regulated expression after certain pharmacological or physiological stimuli. For example, induction of Egr2 mRNA or protein has been observed after seizure activity (Bhat et al., 1992, but see Mack et al., 1992), focal cerebral ischaemia (An et al., 1992), kainic acid injection (Gass et al., 1994), dopamine receptor activation and opiate withdrawal (Bhat et al., 1992), and in hippocampal neurons following LTP-inducing stimuli (Williams et al., 1995; Worley et al., 1993). To our knowledge, the only available study in which the expression of Egr2 was examined after behavioural learning showed no evidence for a regulated expression of Egr2 in structures such as the amygdala, hippocampus or cortex that could be attributed to learning in a single-trial contextual fear conditioning paradigm (Malkani and Rosen, 2000). Research into the functional role of Egr2 in the adult brain has been hampered by the fact that mutant mice carrying two Egr2-null alleles show high perinatal lethality (Swiatek and Gridley, 1993; Topilko et al., 1994). At birth the mice display perturbations of ingestive and respiratory functions and $\sim 70 \%$ die within 24 hours, the remaining $30 \%$ dying within 1-2 weeks, a short lifespan presumably due to defects in hindbrain rythmogenic neural networks controlling respiratory functions (Jacquin et al., 1996; Topilko et al., 1994).

Thus, to investigate whether Egr2 has a role in learning and memory, we generated Egr2 conditional mutant mice based on a floxed allele allowing postnatal, CaMKII-promoter-dependent forebrain-specific Egr2 Cre-mediated excision. We then examined motor function, exploratory behaviour, emotional reactivity and learning and memory performance in a variety of behavioural tasks. Surprisingly, our results reveal that forebrain Egr2-deficiency does not result in learning or memory impairments in these tasks. On the contrary, a facilitation of performance is observed in certain tasks in Egr2-deficient mice. Analyses of basal and brain stimulation-induced expression of other Egr family members suggest that the absence of deficits and the gain of function in certain tasks in Egr2-deficient mice is not due to compensatory expression of Egr1 or Egr3.

\section{MATERIAL AND METHODS}

Generation of Egr2 conditional knock-out mice and genotyping

To generate Egr2 conditional mutant mice, Egr2 ${ }^{\text {lacz/+ }}$ mice (SchneiderMaunoury et al., 1993) were mated with CaMKII-Cre mice (Mantamadiotis et al., 2002) to generate CaMKII-Cre; Egr2lacZ/+ animals. CaMKIICre;Egr2 ${ }^{\text {lacz/ }+}$ adult males were subsequently crossed with Egr2 ${ }^{\text {flox/flox }}$ females in order to generate conditional mutants (CaMKII-Cre; $E_{\text {Er2 }}{ }^{\text {lacZfflox }}$ ), as well as various littermates including mice that were considered as heterozygous (Egr2 $\left.{ }^{\text {lacZ/flox }}\right)$ and controls $\left(\right.$ Egr $\left.^{\text {flox/+ }}\right)$. All lines were maintained in a mixed B6/D2 background. Genotyping of the different alleles was performed by PCR on tail DNA as previously described (Decker et al., 2006). Briefly, we used primers specific for the Cre gene, (5-GTCCGGGCTGCCACGACCAA-3 and 5-ACGGAAATCCATCGCTCGACCAGT-3), the Egr2 ${ }^{\text {flox }}$ allele (5-GTGTCGCGCGTCAGCATGCGTG-3 and 5-GGGAGCGAAGCTACTCGGATACGG-3), and the Egr2 ${ }^{\text {lacz }}$ allele (5GTCGTITACAACGTCGTGACT-3 and 5-GATGGGCGCATCGTAACCGTGC-3). Recombinant DNA and animal manipulations were performed according to French and European Union regulations.

\section{Detection of Cre-mediated deletion of the Egr2 gene}

To characterise the deletion of the floxed Egr2 allele, DNA was extracted from different brain regions and analyzed by PCR. Samples of different brain tissues (cerebral cortex, CA1 hippocampal subfield, dentate gyrus, striatum and cerebellum) were dissected out from conditional mutant mice (CaMKII-Cre; Egr2 $\left.{ }^{\text {lacz/flox }}\right)$ and control animals $\left(E g r 2^{f l o x /+}\right)$ and frozen in liquid nitrogen. Genomic DNA was extracted by performing an enzymatic digestion $\left(400 \mu \mathrm{g} / \mathrm{ml}\right.$ proteinase $\mathrm{K}$ overnight at $37^{\circ} \mathrm{C}$ with agitation) and mechanical dissociation. After phenol/chloroform extraction and ethanol precipitation, DNA concentration of the samples was homogenised and $1 \mu \mathrm{g}$ of DNA was used as template for PCR amplification using the following primers (Figure 1A; Decker et al., 2006; Taillebourg et al., 2002): p2, 5-AGTTGACAGCCCGAGTCCAGTGG-3; p3, 5-GTGTCGCGCGTCAGCATGCGTG-3; p4, 5-GGGAGCGAAGCTACTCGGATACGG-3. Primers $p 3$ and $p 4$ of wild type and Egr2 ${ }^{\text {flox }}$ alleles generate 160 and 195 bp DNA fragments, respectively, whereas primers p2 and p3 amplify a 210 bp DNA fragment from the excised Egr2 allele.

\section{Immunohistochemistry}

Mice were deeply anaesthetised with sodium pentobarbital and perfused transcardially with PBS followed by $4 \%$ paraformaldehyde in phosphate buffer (PB $0.1 \mathrm{M}$ ). Brains were removed, post-fixed overnight and then transferred into $30 \%$ sucrose. Sections were cut coronally $(40 \mu \mathrm{m})$ on cryostat. Free-floating sections were washed several times in PBS (0.1 M). 

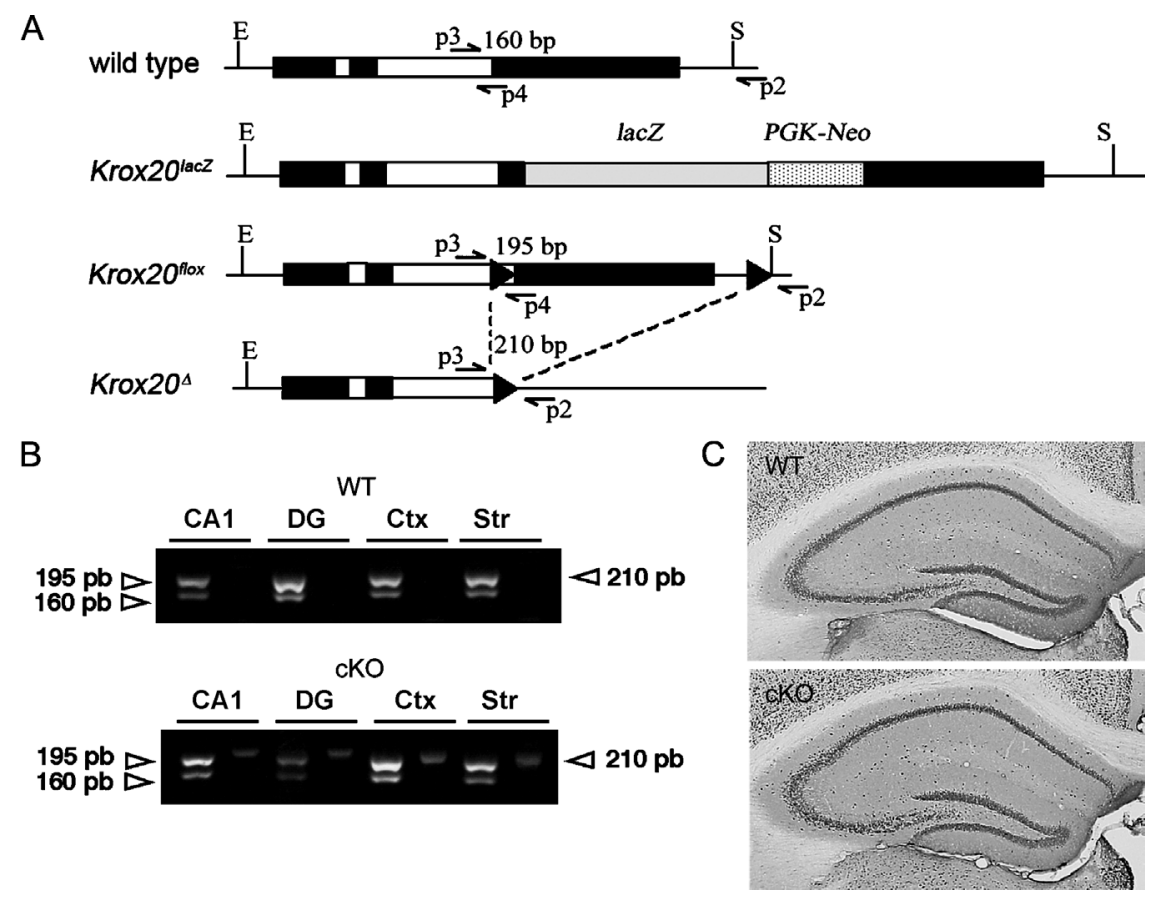

Figure 1. Conditional excision of the floxed allele. (A) Schematic representation of the different Egr2/Krox20 alleles: wild type, Krox20 lacZ, floxed (Krox20 flox) and deleted $\left(K r o x 20^{\Delta}\right)$ alleles. LoxP sites are indicated by black arrowheads. Arrows indicate the positions of the primers used for PCR amplification and the sizes of the amplified fragments are shown above the fragments. Primers $p 3$ and $p 4$ produce 160 and $195 \mathrm{bp}$ fragments from wild type and Krox2 flox alleles, respectively; primers p2 and p3 amplify a 210 bp fragment from the Krox $20^{\Delta}$ allele. (B) PCR analysis of different forebrain regions from wild type (WT) and conditional mutant (cKO) animals. Presence of the Krox20 wild type or lacZ knock-in alleles is revealed by the amplification of a 160 bp fragment and of the floxed allele by a 195 bp fragment, respectively (see Figure 1A). The excision of the second Krox20 exon leading to inactivation is demonstrated by the appearance of the 210 bp PCR fragment only in the conditional mutant (Krox20 lacZ/flox , CaMKII-Cre). Mice without Cre (Krox20 flox/+ $)$ do not show this excision. CA1, area CA1 of the hippocampus; DG, dentate gyrus; Ctx, cortex, Str; striatum. (C) NeuN immunoreactivity. Gross hippocampal anatomy appeared similar in WT and cKO mice.

Endogenous peroxydase was inhibited by a 15 minutes treatment with $10 \%$ hydrogen peroxide and $10 \%$ methanol solution. Non-specific epitopes were blocked by incubation in $5 \%$ normal horse serum and $0.25 \%$ Triton X-100 in PBS for 30 minutes. Sections were incubated with the primary mouse anti-NeuN monoclonal antibody (1/600, Abcys) overnight at room temperature, then washed three times in PBS and incubated with a biotinylated horse anti-mouse secondary antibody (1/ 400 , Abcys) for 2 hours at room temperature. Immunostaining was visualised using $\mathrm{ABC}$ elite system (Vector Labs) and a Vector VIP substrate kit (Vector Labs).

\section{Western blotting}

Mouse brains were rapidly removed; the dentate gyrus and CA1 hippocampal area from both sides of the brain were dissected on ice and lysed in solubilisation buffer $(10 \mathrm{mM}$ Tris- $\mathrm{Cl}, 50 \mathrm{mM} \mathrm{NaCl}, 1 \%$ Triton X100, $30 \mathrm{mM}$ sodium pyrophosphate, $50 \mathrm{mM} \mathrm{NaF}, 5 \mathrm{mM} \mathrm{ZnCl}, 100 \mathrm{mM}$ $\mathrm{Na}_{3} \mathrm{VO}_{4}, 1 \mathrm{mM}$ DTT, $5 \mathrm{nM}$ okadaic acid, $2.5 \mathrm{mg}$ of aprotinin, $2.5 \mathrm{mg}$ of pepstatin, $0.5 \mathrm{mM}$ PMSF, $0.5 \mathrm{mM}$ benzamidine and $2.5 \mathrm{mg}$ of leupeptin). The homogenates were incubated for 20 minutes at $4^{\circ} \mathrm{C}$ and insoluble material was removed by centrifugation $(13000 \mathrm{rpm}$ for 20 minutes at $\left.4^{\circ} \mathrm{C}\right)$. Supernatants were collected, aliquoted and then stored at $-80^{\circ} \mathrm{C}$. Protein concentrations were determined using Bradford protein assay (Biorad), with the samples equalised and denatured by boiling in sample buffer $(0.5 \mathrm{mM}$ Tris- $\mathrm{HCl}$, pH 6.8; 10\% glycerol, $10 \%$ SDS, $5 \%$ $\beta$-mercaptoethanol and $0.05 \% \mathrm{~W}: \mathrm{V}$ brophenol blue).

Twenty micrograms of extracted protein was separated by $10 \%$ SDSPAGE before electrophoretic transfer onto nitrocellulose membrane (Biorad). Blots were blocked in 5\% non-fat milk in Tris-buffered saline (TBS) with Tween-20 (TBS-T; $50 \mathrm{mM}$ Tris (pH7.4), $150 \mathrm{mM} \mathrm{NaCl}$ and
$0.05 \%$ Tween 20). They were probed overnight at $4^{\circ} \mathrm{C}$ with primary antibody diluted in $2 \%$ non-fat milk/TBS-T [anti-Egr1 (sc-110, Santa Cruz), anti-Egr2 (Covance), anti-Egr3 (sc-191, Santa Cruz) and anti-Actin (Sigma)]. Membranes were then incubated for 2 hours at room temperature with a peroxydase-conjugated goat anti-rabbit secondary antibody (Amersham). Blots were developed using ECL plus Western blotting reagents (Amersham) and finally exposed to film. All blots were probed for regulation of Egr1, Egr2, Egr3 and Actin; antibodies were stripped for the blot with Reblot (Chemicon Intentional) and three replicates per sample were made. Optical density of protein bands were analysed with GeneTools analysis software (GeneGenius gel analysis systems, Syngene, Cambridge, UK). Actin was used to normalise Egr1, Egr2 and Egr3 protein values to control for loading variation. Optical density values were normalised to WT controls. Group differences were analysed with analysis of variance (ANOVA) using SPSS and Student's $t$-tests.

\section{Electroconvulsive shocks}

Maximal electroconvulsive shock (MECS) was administered via ear-clip electrodes using a constant current generator. Mice were anaesthetised lightly with fluothane and a single $100 \mathrm{~V}$ shock was delivered for a duration of 2 seconds. Immediately following the shock, mice displayed tonicclonic seizures and were placed back in their home cages for 2 hours. Control mice were treated in the same manner with the exception of delivery of MECS.

\section{Animals and general behavioural procedures}

Mouse siblings were kept in groups (2-6 per cage) under a standard 12:12 hours light/dark cycle (lights on at 7:00 a.m.) with food and water ad 
libitum, with the exception that they were placed in individual cages 1 week before the conditioned taste aversion task. Behavioural testing was undertaken between $8 \mathrm{a}$.m. and $8 \mathrm{p}$.m. after daily handling for 1 week. A total of 61 male mice (23WT, $16 \mathrm{HT}, 22 \mathrm{cKO}$ ) aged 4-12 months, and distributed across three cohorts were used. Two were tested on a battery of tests in the following order: grid-suspension and traction reflex tests, rotarod test, elevated-plus maze, open field activity, object recognition, water maze place navigation, conditioned taste aversion and trace fear conditioning. The third cohort was tested on the object recognition task. All experiments were conducted blind to the genotype, and in accordance with the recommendations of the EU directive (86/609/EEC) and the French National Committee (87/848).

\section{Motor coordination and motor skill learning}

Sensorimotor abilities, muscle strength and motor coordination were evaluated in the inverted grid test and wire suspension test (Vaillend et al., 2004). In the inverted grid test, each mouse was placed in the middle of a wire grid inverted at a $180^{\circ}$ angle, and time for the mice to remain upside down on the grid was counted, with a maximum of 60 seconds if the mouse did not fall. In the wire suspension test, forepaws of each mouse were placed on a thin horizontal wire $(1.5 \mathrm{~mm}$ in diameter) $35 \mathrm{~cm}$ above a table surface. Latency to bring at least one hind-paw up to grip the wire was recorded. Each mouse was given 3 trials (10 minutes inter-trial interval, ITI) and the mean was calculated per mouse. Each trial lasted for a maximum of 25 seconds. Motor coordination, balance and skill learning were evaluated using the rotarod test under three conditions: a stationary rod (60 seconds maximum), a rotating rod with a constant speed ( $4 \mathrm{rpm}$ for 60 seconds maximum), and a rod that had an accelerating speed (140 rpm over 0-300 seconds) for motor skill learning. Mice were submitted to three training sessions, 2 days apart, each consisting of one trial on the stationary rod, two trials on the constant-speed rotarod, and two trials on the accelerating rotarod (10 minutes ITI). Time spent on the rod in each condition was measured.

\section{Emotional reactivity}

The elevated plus-maze (black-hard plastic, $65 \mathrm{~cm}$ above the floor, equipped with a video camera) had two facing arms enclosed with high walls $(20 \times 8 \times 25 \mathrm{~cm})$, two open arms $(20 \times 8 \mathrm{~cm})$ and a central area $(8 \times 8 \mathrm{~cm})$ to form a plus sign. Illumination was 150 lux in open and 30 lux in enclosed arms. Each mouse was placed in the central area with the head facing an open arm and observed for one 15-minute session. Number of entries and time spent in open and enclosed arms were recorded.

\section{Open field activity and object recognition}

The test box consisted of a square open field $(50 \times 50 \times 50 \mathrm{~cm})$ with black walls and a white floor covered with sawdust. A video recording camera was placed above the open field arena to record and input activity to a computer. Experiments were undertaken under homogeneous dim illumination ( $<50$ lux). Two objects were placed in the box, near the corners $(15 \mathrm{~cm}$ from the walls). The objects used were small wooden or plastic toys of different colours and shapes $(3-6 \mathrm{~cm}$ diameter $\times 3-6 \mathrm{~cm}$ high) or made out of Lego ${ }^{\circledR}$ pieces $(6 \times 4 \times 3.5 \mathrm{~cm})$. The objects and their spatial arrangement in the test box were chosen in a pseudorandom order and were counterbalanced between mice. The testing procedure started with a 4-day period of habituation consisting of two daily sessions of 10 minutes separated by a 5-hour delay, as previously described (Poirier et al., 2007; Vaillend et al., 2004). On day 1, littermate mice from a given cage were placed all at once in the empty open field and allowed to move freely for 10 minutes. On days 2-3, mice were individually exposed to the open field and spontaneous locomotor activity was recorded. On day 4 , two identical plastic objects, not subsequently used, were placed in the box for 10 minutes. The object discrimination tasks started 48 hours after habituation. Each experiment consisted of a single acquisition session
( 3 trials of 5 minutes with a 5 -minute ITI) followed by a retention test (2 trials of 5 minutes with a 5-minute ITI) 10 minutes or 24 hours later in independent groups where one of the two objects was replaced by a novel object. Object changes during the test phase were counterbalanced among individuals and genotypes. Mouse behaviour was recorded and analysed using the Any-Maze Video Tracking System (version 4.5). Parameters recorded included horizontal (total distance moved in metres, mean speed in $\mathrm{m} / \mathrm{s}$ ) and vertical activity (number of rears) in the entire arena and in two specific zones: centre of the arena $(40 \times 40 \mathrm{~cm})$ and periphery $(5 \mathrm{~cm}$ from the walls). Latency of the first contact with an object and time spent in contact with it were recorded during acquisition and retention. Contact was defined as the mouse's snout or paws touching the object. Retention performance was expressed as the per cent time spent exploring the novel object over total object exploration time.

\section{Conditioned taste aversion}

Three days prior to testing, mice were placed on a water-restriction regime with access to water for 30 minutes/day, from two identical bottles in their home cages. The bottles were weighed to evaluate fluid consumption. On the conditioning day, mice had free access to a $15 \%$ sucrose solution for 30 minutes in two identical bottles. One hour later, mice were injected (i.p.) with either $0.9 \%$ saline, or lithium chloride (LiCl: $0.3 \mathrm{M}, 2 \%$ body weight). Twenty-four hours later, mice were given a twobottle choice test between water and sucrose for 30 minutes. The relative position of the two bottles was counterbalanced between mice. Conditioned taste aversion was expressed as the per cent sucrose solution consumed over total fluid intake.

\section{Trace fear conditioning}

Training was conducted in a conditioning chamber $(19 \times 25 \times 19 \mathrm{~cm})$ equipped with black methacrylate walls, transparent front door, a speaker and grid floor, placed inside an outer sound-attenuating chamber (StartFear System, Panlab). A computer program (Freezing Software, StartFear System, Panlab) controlled the audio generator to deliver the tone CS ( 15 seconds, $80 \mathrm{~dB}, 1000 \mathrm{~Hz}$ ) and a shock generator wired to the grid floor that generated a scrambled foot-shock as US (2 seconds, $0.2 \mathrm{~mA})$. The conditioning context was cleaned with $100 \%$ ethanol between each mouse. In trace fear conditioning, the CS and US are separated in time by a trace interval. Thus, on the training day, mice were individually placed into the conditioning chamber, allowed to explore for 3 minutes, and then presented with a total of six CS-trace-US pairing with a 30 -second trace interval and a 180 -second ITI. The mice were removed from the conditioning chamber 3 minutes after the last shock and returned to their home cages. Twenty-four hours later, a single CS alone test trial was given in a novel chamber, different from the conditioning chamber, which contained new olfactory, tactile and visual cues (plastic white floor, white metal side walls, chamber cleaned prior to test with lemonflavoured solution). The tone test consisted of a 3-minute baseline period followed by 3-minute tone presentation. Freezing during the tone CS and during the trace interval was quantified during learning and test by measuring movements automatically (activity threshold adjusted at 10 and time threshold set at $500 \mathrm{~ms}$ ).

\section{Spatial learning and memory}

Spatial learning and memory were tested in the water maze. The maze consisted of a circular tank ( $150 \mathrm{~cm}$ diameter) filled with water $\left(23-24^{\circ} \mathrm{C}\right)$ to $15 \mathrm{~cm}$ below the top of the sidewall, made opaque by addition of a white non-toxic paint (Opacifier 631, Morton SA, France). A circular escape platform $(10 \mathrm{~cm}$ diameter) was placed in the centre of the maze during pre-training or the centre of a quadrant $(40 \mathrm{~cm}$ from the wall) during training. The platform, placed $0.5 \mathrm{~cm}$ below the water surface, was not visible. The maze was placed in a well-lit room ( 380 lux) containing several extra-maze cues. A video camera, mounted on the ceiling above the maze to record swim paths, was connected to a computer located in 
an adjacent room. The day before training, mice underwent two pretraining sessions (four trials in the morning and afternoon). A habituation session started with the mouse standing on the platform for 60 seconds in the centre of the maze. Then, a trial started by introducing the mouse into the maze facing the wall at one of the four designated starting points in a pseudorandom order. Immediately, the mouse was gently guided by hand to the platform and allowed to remain on it for 60 seconds. After habituation, mice were trained to find the platform in one quadrant for 9 days with two blocks, 5 hours apart, of four trials a day. During each block, the mouse was introduced into the water maze from three different starting points and allowed to swim freely until it reached the platform. Mice failing to find the platform after 90 seconds were gently guided to it by hand and a maximum escape latency of 90 seconds was recorded. Mice were allowed to remain 60 seconds on the platform before the start of the next trial. Probe tests were performed 24 hours and 7 days after the last training session. They consisted of a single trial during which the platform was removed and mice were allowed to search the platform for 90 seconds. Immediately after the first probe test, mice were given four additional training trials to prevent extinction. Data recorded by videotracking (Any-Maze Video Tracking System) were used to reconstruct swim paths and to calculate averaged swim speed, swim path lengths and time spent in various virtual areas of the maze: the four quadrants, the four platform annuli, four extended annuli of $48 \mathrm{~cm}$ in diameter beyond that of the platform, and a virtual corridor $19 \mathrm{~cm}$ in width, set along the wall to quantify thigmotaxis. Performance in probe tests was evaluated by comparing to chance (25\%) the time spent in the quadrant that previously contained the platform and the number of crosses over the platform site.

\section{Statistical analysis}

Data were analysed using analysis of variance (one-way, two-way, or repeated-measures analysis of variance as appropriate; Statview 5.0 program), with post hoc comparisons (Fisher's protected least significant difference with Bonferroni's and Dunn's correction) when required. An alpha value of $p<0.05$ was considered statistically significant.

\section{RESULTS \\ Generation and characterisation of conditional Egr2-deficient mice}

Mice carrying two Egr2 null alleles die shortly after birth (Jacquin et al., 1996; Swiatek and Gridley, 1993; Topilko et al., 1994). To circumvent this problem, we generated a conditional Egr2 knock-out mouse. This was obtained by combining two Egr2 alleles, Egr2 ${ }^{\text {lacZ }}$, a knock-in of the lacZ coding sequence, which is null in terms of Egr2 activity (SchneiderMaunoury et al., 1993), and Egr2 flox , a floxed allele that is fully functional but can be inactivated upon Cre recombination to give $\mathrm{Egr}^{ }{ }^{\text {(Figure 1A; }}$ Decker et al., 2006; Taillebourg et al., 2002), with a Cre driver transgene, CaMKII-Cre, whose expression is restricted to forebrain neurons (Mantamadiotis et al., 2002). Therefore, in the conditional mutants (CaMKII-Cre; Egr2 ${ }^{\text {lacz/flox }}$ ), herewith referred as conditional knock-out mice (cKO), Egr2 should be inactivated in forebrain neurons, whereas one allele should be functional in all other cell types. In the course of the generation of the conditional mutants, littermates with different genotypes were obtained, which were used as controls. Therefore, in the following experiments, Egr2 ${ }^{\text {lacz/flox }}$ animals will be referred to as heterozygous (HT) and $E g r 2^{f l o x /+}$ animals as wild type (WT), since in the absence of Cre driver the floxed allele behaves as wild type.

To verify that recombination occurred as expected in forebrain neurons, we dissected tissues from WT and cKO mice and performed PCR analyses to detect wild type, lacZ, floxed and deleted alleles (Figure 1A). In hippocampal area CA1, dentate gyrus, cortex and striatum from WT animals, we found that the floxed allele was not recombined since the PCR fragment corresponding to the deleted allele was not observed (Figure 1B). In contrast, in the cKO mice, presence of the deleted allele was attested by this analysis in all these tissues (Figure 1B), establishing that recombination occurred as expected, leading to complete inactivation of Egr2 in at least part of the cells.

\section{General behavioural and brain anatomy of conditional Egr2-deficient mice}

Conditional knock-out (cKO) and heterozygous (HT) mice appeared healthy and showed no overtly abnormal behaviour. Body weights of cKO $(35.71 \pm 1.4 \mathrm{~g}, \quad n=14)$ and HT mice $(32.81 \pm 1.02 \mathrm{~g}, n=11)$ were similar to that of their littermate WT controls $(35.64 \pm 1.23 \mathrm{~g}, n=14$; $F(2,36)=1.848$, ns). The basic neuronal architecture of the brain and hippocampal anatomy assessed by immunohistochemical analysis with the nuclear marker NeuN in $\mathrm{CKO}$ and $\mathrm{HT}$ mice were indistinguishable from that of control mice (Figure 1C).

\section{Muscle strength, locomotor activity and emotional reactivity}

Egr2-deficient mice were not impaired in sensorimotor tests involving muscle strength and motor coordination. In the inverted grid test, the mean time to remain suspended to the grid was slightly longer in HT mice ( $59 \pm 0.60$ seconds, $n=11$ ) compared to the two other genotypes (genotype effect $F(2,36)=5.501, p=0.008$ ), but it was similar in WT $(37,92 \pm 6.15$ seconds; $n=14)$ and cK0 mice $(35.50 \pm 5.75$ seconds, $n=14)$. In the traction reflex test, there was no significant genotype effect on the mean latency to bring hind-paws up to the wire across the three consecutive trials (cK0: $15.14 \pm 1.51$ seconds, $n=14 ; \quad \mathrm{HT}$ : $11.03 \pm 1.65$ seconds, $\quad n=11 ; \quad$ WT: $11.95 \pm 1.23$ seconds, $\quad n=14$; genotype effect $F(2.36)=1.312$, ns). Locomotor and exploratory activity assessed on first occurrence in the open field revealed no significant difference between genotypes in total distance travelled, mean speed, vertical activity (rearings), distance travelled and time spent in centre (data not shown). Habituation of locomotor and exploratory activity over five sessions in the open field also showed no significant difference between the three genotypes for any of the measured parameters (data not shown). The elevated plus maze was used to evaluate anxiety-related behaviour by measuring avoidance of the open arms. Per cent entries into, and per cent time spent on open arms were not different between genotypes (per cent entries: WT: $11.18 \pm 2.42 \%, n=14$; HT: $13.19 \pm 2.8 \%, n=11$; cKO: $9.8 \pm 4.46 \%, n=14$; genotype effect $F(2,36)=0.229$, ns; per cent time: WT: $1.54 \pm 0.63 \%, n=14$; HT: $1.73 \pm 0.96 \%, n=11$; cKO: $1.33 \pm 0.6 \%, n=14$; genotype effect $F(2,36)=0.073$, ns; data not shown). These data suggest that $c K 0$ and HT mice have normal locomotor and exploratory behaviour, and do not show signs of anxiety disturbances.

\section{Motor coordination and motor skill learning}

Motor coordination and balance was assessed in the rotarod test, using a stationary and a rotating rod at relatively low $(4 \mathrm{rpm})$ and constant speed. Mice from the three genotypes (WT: $n=14$; HT: $n=11$; cKO: $n=14$ ) showed good performance in this task across the three training sessions, as shown by a mean time remaining on the constant-speed rotating rod close to the 60 -second maximum (Figures $2 \mathrm{~A}$ and $2 \mathrm{~B}$ ). There was no significant difference between genotypes $(F(2,36)=1.55$, ns) and no significant trial by genotype interaction $(F(10,180)=1.042$, ns). On sessions with an accelerating rod (1-40 rpm over 300 seconds), all mice progressively improved their performance with successive trials and sessions (Figure 2C). However, performance of cKO mice improved more rapidly than that of WT mice, as shown by a significant difference on trial 3 and 4 (Figure 2C; $p<0.05$ ), and a significant difference in cumulated mean time to fall from the rod across the three sessions $(152.95 \pm 8.88 \mathrm{~s}$ in cK0 mice and $110.31 \pm 8.18 \mathrm{~s}$ in WT controls) (Figure 2D; Fisher's PLSD post hoc analysis $p=0.0271$ ). Performance of heterozygous mice ( $144.10 \pm 14.15$ seconds) was also higher than that of WT controls (Figures 2C and 2D), although the difference did not reach 
Constant speed (4 rpm)

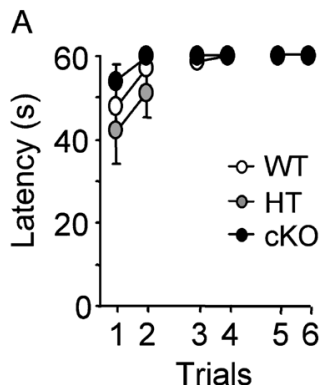

B

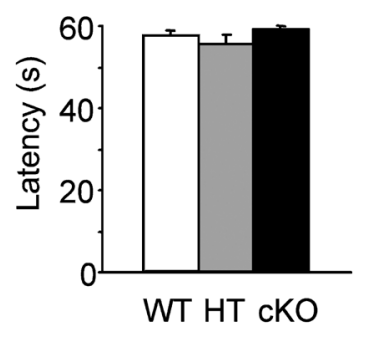

Accelerating speed $(0 \rightarrow 40 \mathrm{rpm})$

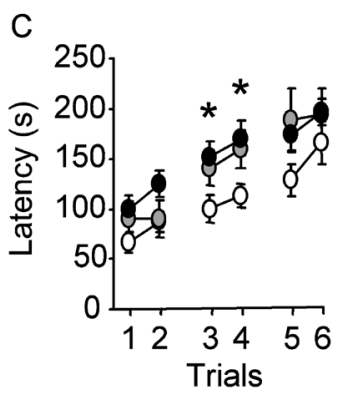

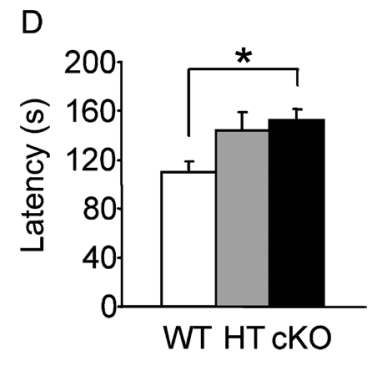

Figure 2. Motor coordination and motor skill learning in the rotarod. (A, B) Performance on the rotating rod at constant speed measured by the latency to fall from the rod during three daily sessions of two trials $(\boldsymbol{A})$ and cumulative histograms of the mean latency to fall over the three sessions (B). Performance of the mice was close to maximum ( 60 seconds) and there was no significant difference between genotypes. (C,D) Motor skill training consisted in three sessions of two trials on the rotating rod with a regularly accelerating speed over the 300 seconds of each trial. Performance improved progressively with training in all mice, however, performance of cKO and HT mice improved faster than that of WT mice (C). Cumulative histograms of the mean latency to fall showed a significant improvement of performance in cKO mice compared to WT mice. ${ }^{*} p<0.05$.

statistical significance. In all, these results suggest a facilitation of performance in this motor skill learning task in cKO mice.

\section{Learning and memory}

Spatial learning and memory was assessed in a navigation task in the water maze where mice learn to locate the position of a hidden platform. Over the 9 days of water maze training, WT $(n=10), \mathrm{HT}(n=9)$ and cKO $(n=10)$ mice required progressively less time to locate the hidden platform $(F(17,442)=26.98, p<0.0001$; Figure $3 A)$. Similar acquisition curves were observed in the three genotypes (genotype effect: $F(2,26)=0.261$, ns; genotype by blocks of trials interaction: $F(34,442)=0.86$, ns; Figure $3 A$ ), indicating that WT, HT and cKO mice learned to locate the platform position at a similar rate during training. No significant difference between the three genotypes was found in the distance swam to reach the platform (genotype effect: $F(2,26)=0.247$, ns; genotype by blocks of trials interaction: $F(34,442)=0.887$, ns), swim speed (genotype effect: $F(2,26)=1.146$, ns; genotype by blocks of trials interaction: $F(34,442)=1.103$, ns) or thigmotaxis, an index of anxiety characterised by motion along the walls (genotype effect: $F(2,26)=$ 0.273 , ns; genotype by blocks of trials interaction: $F(34,442)=0.847$, ns; data not shown). Spatial memory was evaluated during probe trials given 24 hours and 7 days after the last training session. At the 24-hour delay, all genotypes showed a strong preference for the target quadrant where the platform was located during training (Figure 3B; $F(3,78)=56.02$, $p<0.0001$ ) and the percentage of time spent by WT, HT and cKO mice in the target quadrant was significantly higher than chance (all $p$ values
$<0.002$ ). No difference was found between groups in the annulus crossing index (WT: $5.2 \pm 0.998$; HT: $3.44 \pm 0.55$; cKO: $5.1 \pm 0.98$; $F(2,26)=1.21, \mathrm{~ns})$. In the second probe trial given 7 days later, mice from all genotypes still preferentially spent more time in the target quadrant $(F(3,78)=27.186, p<0.0001)$, with a time spent in the target quadrant significantly above chance (Figure $3 \mathrm{C}$; all $p$ values $<0.02$ ). Thus, $\mathrm{CKO}$ and HT mutant mice showed normal spatial learning and normal long-term spatial reference memory.

Fear memory was assessed in a trace fear-conditioning paradigm in which animals learn to associate an auditory stimulus as CS with a footshock as US, with the CS and US separated in time by a 30 -second trace interval. The evolution of freezing behaviour during the tone (Figure 4A) and during the trace interval (Figure 4B) showed that WT $(n=8)$, HT $(n=8)$ and cKO $(n=8)$ mice progressively learned the association between the CS and the US as training progressed, with a similar rate of increasing freezing responses to the tone CS $(F(5,105)=23.41$, $p<0.001)$ and during the trace interval $(F(5,105)=12.538$, $p<0.0001$ ). The amount of freezing during the tone (Figure 4A) was slightly less in $\mathrm{CKO}$ and $\mathrm{HT}$ mice than in WT mice, however, statistical analysis revealed no significant effect of genotype $(F(2,21=3.418$, ns) or trial by genotype interaction $(F(10,105=0.79$, ns). Similarly, there was no effect of genotype $(F(2,21)=0.212$, ns) and no significant trial by genotype interaction $(F(10,105)=0.606$, ns) in conditioned freezing during the trace interval (Figure 4B). Retention was tested 24 hours after the end of conditioning by presenting a 3-minute CS alone test trial in a novel context. Again, WT, HT and cKO mice showed significant freezing to the tone (Figure $4 \mathrm{C} ; F(1,21)=38.038, p<0.0001$, compared to the
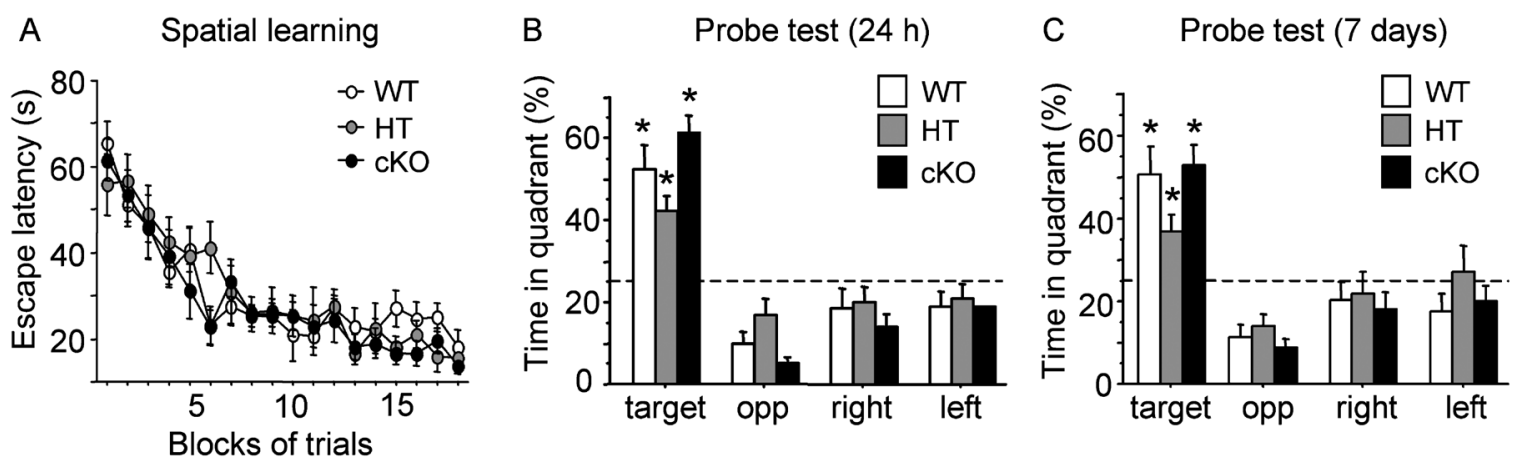

Figure 3. Spatial learning in the water maze. During acquisition, all mice learned to locate the hidden platform at similar rate as shown by a comparable rate of decay of the escape latency (A). In probe trials given 24 hours (B) or 7 days (C) later, WT, HT and cKO mice showed retention of the learning expressed by a spatial bias for the training quadrant. ${ }^{\star} p<0.05$. 
A

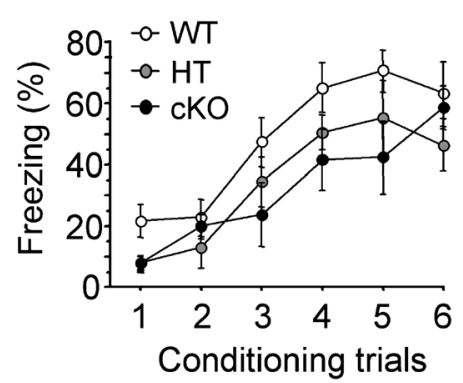

B

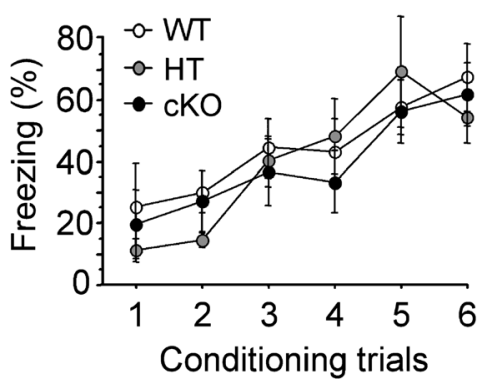

C

Retention (24h)

Figure 4. Trace fear conditioning. Mice were subjected to six tone (CS)-footshock (US) paired trials with a CS-US trace interval of 30 seconds. (A, B) Learning curves expressed as the per cent freezing to the tone CS (A) and during the trace interval (B) during conditioning showed no significant difference between genotypes. (C) The tone test was performed 24 hours after conditioning in a different context. WT, HT and cKO mice showed significant freezing to the tone compared to the pre-tone period, with no significant difference between genotypes, indicating that Egr2-deficiency did not disrupt trace fear conditioning or memory.

pre-tone period) with no difference between genotypes $(F(2,21)=1.818$, ns). Thus, Egr2-deficency affected neither trace fear conditioning nor fear memory in this paradigm.

We next tested associative memory in a conditioned taste aversion paradigm in which water-deprived mice learn to associate a novel taste ( $15 \%$ sucrose solution) with a malaise induced by injection of lithium chloride. Independent groups of mice of the three genotypes served as controls and were given the sucrose solution, but were injected with sodium chloride instead of lithium chloride. When mice were offered a choice between water and sucrose solutions 24 hours after training, conditioned WT $(n=7)$, HT $(n=6)$ and cKO $(n=8)$ mice injected with lithium chloride showed a strong aversion for sucrose (Figure 5A) while, as expected, a slight preference for sucrose was observed in control WT $(n=7), \mathrm{HT}(n=5)$ and cKO $(n=6)$ mice injected with sodium chloride (Figure $5 \mathrm{~A}$ ). Statistical analysis of the aversion index revealed a significant effect of treatment $(F(1,33)=63.37, p<0.0001)$, but no significant effect of genotype $(F(2,33)=0.215$, ns) or genotype by treatment interaction $(F(2,33)=0.43$; ns). The total volume consumed was similar in the three groups $(F(2,36)=0.20$, ns). These results suggest that long-term associative taste memory is not affected by Egr2 loss-of-function.

To assess short-and long-term recognition memory, we used an object recognition task based on the innate propensity of rodents to explore novelty and in which mice, after having been briefly familiarised with two objects, can demonstrate they remember the objects after a delay by showing preferential exploration of a novel object. When mice were allowed to explore objects for the first time, statistical difference in the number of contacts with an object was neither found between genotypes (WT: $17.69 \pm 1.44, n=23$; HT: $20.09 \pm 1.60, n=16$; cK0: $18.36 \pm 1.23$, $n=22 ; F(2,58)=0.42, n s)$, nor in the percentage of time spent exploring the objects (WT: $8.40 \pm 1.06 \%, n=23$; HT: $8.24 \pm 1.03 \%, n=16$; cKO: $11.17 \pm 1.10 \%, n=22 ; F(2,58)=1.401$, ns), indicating intact noveltyseeking behaviour in mutant mice. Mice of three genotypes also showed comparable exploration times when they were then exposed to objects
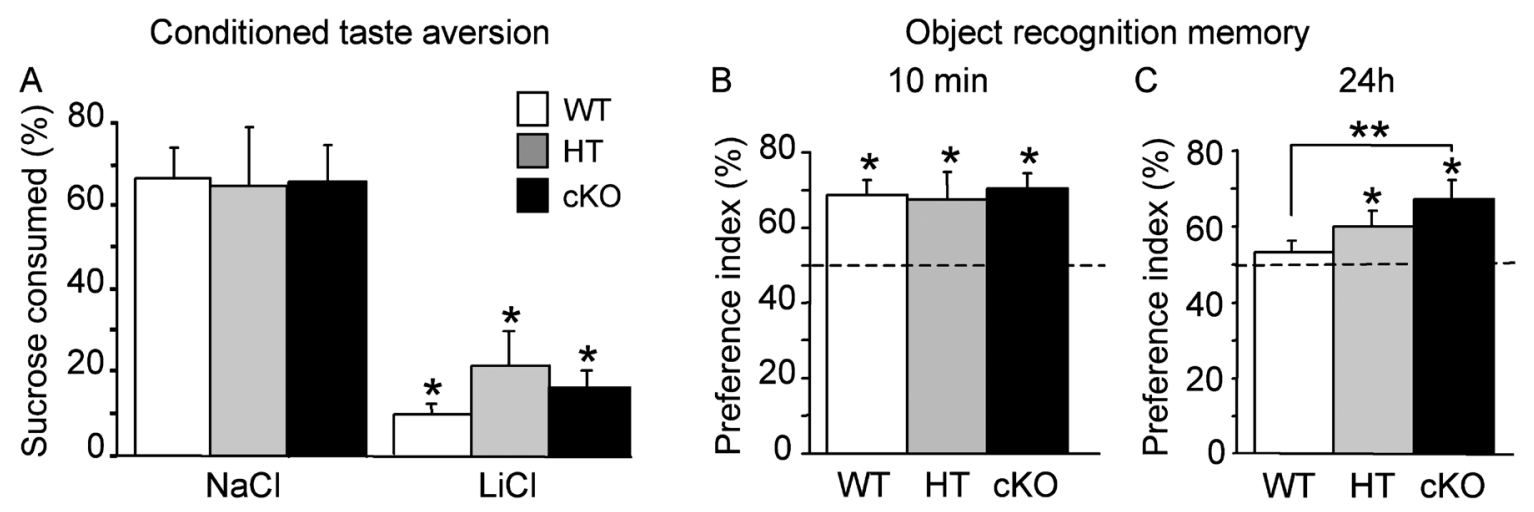

Figure 5. Conditioned taste aversion and recognition memory. (A) Conditioned aversion task was not affected by Egr2 loss-of-function. Histograms represent per cent sucrose consumed out of total volume consumed 24 hours after exposure to novel sucrose solution followed by intraperitoneal injection of lithium chloride (LiCl) as US or sodium chloride ( $\mathrm{NaCl}$ ) as control. When sucrose was associated with LiCl injection, WT, HT and cKO mice all showed a strong and significant aversion to sucrose during the choice test 24 hours after conditioning. Control mice of the three genotypes in which sucrose was followed by NaCl injection showed a slight preference for sucrose over water. $(\boldsymbol{B}, \boldsymbol{C})$ Object recognition memory. Mice were briefly exposed to two objects and recognition memory was tested in independent groups 10 minutes and 24 hours later with a familiar object replaced by a novel object. Retention performance is expressed as the group mean ( $\pm S E M)$ preference index (time spent exploring the novel object/total time of object exploration $\times 100)$. (B) Mice of the three genotypes spent significantly more time exploring the novel object at the 10-minute delay, showing good short-term recognition memory. (C) After a 24-hour delay, WT mice no longer showed a preference for the novel object with the protocol used in this study, whereas both HT and cKO mice still spent more time exploring the novel object, indicating facilitation of long-term recognition memory. The horizontal line represents equal exploration of the novel and familiar objects. ${ }^{*} p<0.05$ compared to chance; ${ }^{* *} p<0.01$ between groups. 
during the 15-minute acquisition phases of object recognition task (total exploration time, WT: $9.19 \pm 0.76 \%, n=23$; HT: $7.97 \pm 0.59 \%, n=16$; cK0: $8.78 \pm 0.61 \%, n=22 ; F(2,58)=0.32$, ns), indicating that all the mice had the same curiosity and motivation for objects. Retention was tested either 10 minutes or 24 hours after acquisition by replacing one familiar object by a novel object and by measuring the time spent exploring the novel object. At the 10-minute delay, WT $(n=9)$, HT $(n=5)$ and cK0 $(n=8)$ mice spent significantly more time exploring the novel object than the familiar object (all $p$ values $<0.05$; Figure $5 \mathrm{~B}$ ), indicating similar levels of short-term memory. With this acquisition protocol, WT control mice $(n=14)$ did not show evidence for long-term recognition memory at 24 hours (recognition index compared to chance: $p>0.05$; Figure $5 C$ ). In contrast, both $\mathrm{CKO}(n=14)$ and HT $(n=11)$ mice still preferentially explored the novel object at the 24 hours retention delay $(p<0.05$ in each case; Figure $5 \mathrm{C}$ ). Post hoc analysis showed a significant difference between $\mathrm{CKO}$ and WT mice (Fisher's PLSD $p=0.0064$ ) while the performance of HT mice was intermediate. These results indicate that Egr2deficiency is associated with enhanced long-term recognition memory.

\section{Expression of other Egr family members \\ in Egr2-deficient mice}

Western blotting analyses were conducted to assess constitutive and regulated levels of Egr1, Egr2 and Egr3 in the dentate gyrus and CA1 of the hippocampus from WT, $\mathrm{HT}$ and cKO mice ( $n=5$ per genotype). There was no significant difference in the constitutive level for Egr1 $(F<1)$, Egr2 $(F(2,12)=1.2, p>0.05$ or $\operatorname{Egr} 3(F(2,12)=1.21, p>0.05$; (data not shown) proteins in the dentate gyrus. This is not surprising with Egr1 and Egr2 as there is negligible constitutive expression of the proteins in the dentate gyrus (sample blots in Figure 6D); albeit the Egr2 inactivation is restricted to neurons. Although Egr3 showed constitutive expression in the dentate gyrus in agreement with other studies (0'Donovan et al., 1998), expression levels were equivalent in all three genotypes. This suggests that in the absence of Egr2 there is neither compensatory regulation nor a linked detrimental effect on expression of Egr1 and Egr3. Regulation of Egr member proteins was assessed 2 hours following MECS. As expected there was no regulation of Egr2 protein levels in cKO mice following MECS compared with control mice not receiving shock $(t=1.5, p>0.05$; Figures $6 \mathrm{~B}$ and $6 \mathrm{D}$ ). Egr2 was significantly upregulated by MECS in WT and HT mice $(t=17.3, p<0.01$ and $t=5.2, p<0.01$, respectively; Figures $6 \mathrm{~B}$ and $6 \mathrm{D}$ ), with a level of regulation of Egr2 in heterozygous mice approximately half that of WT mice $(t=6.5, p<0.01)$. In contrast, Egr1 proteins were upregulated following MECS in all groups ( $t$-test, all $p$ values $<0.01)$ with no difference in the level of regulation between genotypes $(F<1$; Figures $6 \mathrm{~A}$ and $6 \mathrm{D})$. No MECS-induced regulation of Egr3 was observed at this time point in any of the groups ( $t$-test, all $p$ values $>0.05$; Figures $6 \mathrm{C}$ and $6 \mathrm{D}$ ).

In area CA1 of the hippocampus, Egr1 and Egr3 were constitutively expressed while the Egr2 antibody detected only a weak signal that was close to background (Figure 7D). As in the dentate gyrus, there was no significant difference in the basal levels of expression of Egr proteins between groups (all $F$ values $<1$ ). Also in keeping with the pattern of results observed in the dentate gyrus, there was significant induction of Egr1 in all genotypes following MECS compared with non-stimulated mice ( $t$-test, all $p$ values $<0.05$; Figures $7 \mathrm{~A}$ and $7 \mathrm{D}$ ), and no significant regulation of Egr3 at this time point ( $t$-test, all $p$ values $>0.05$; Figures $7 C$ and 7D). Egr2 was also significantly upregulated in both WT $(t=5.7$, $p<0.01)$ and HT mice $(t=2.4, p<0.05)$ following MECS. In cKO mice, there was a very small increase in Egr2 following MECS that may be due to activation in non-neuronal cells that are not supposed to have undergone Cre-recombination; however, this did not reach statistical significance
A

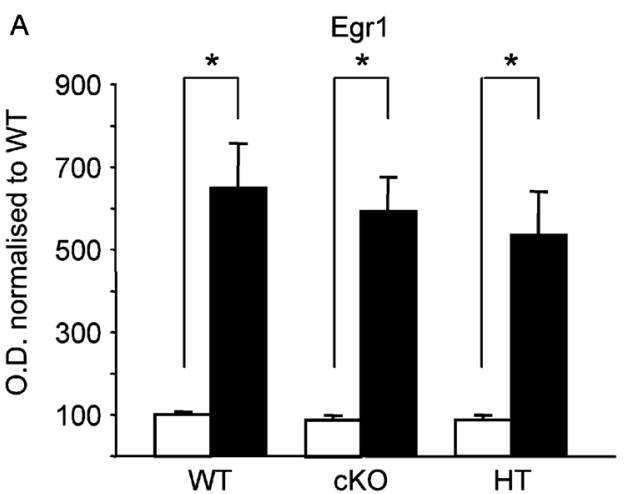

C

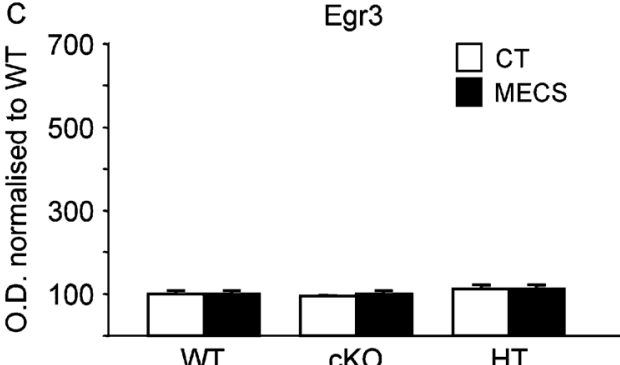

B

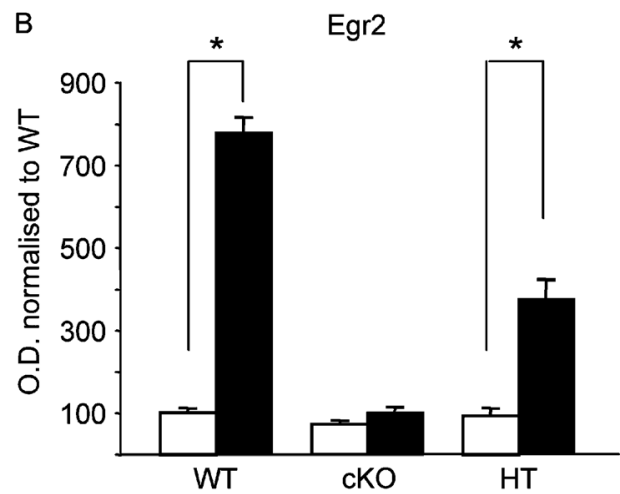

D

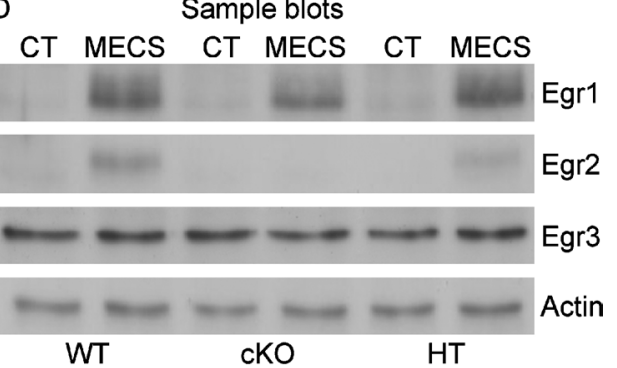

Figure 6. Basal and MECS-induced expression of Egr members in the dentate gyrus. Egr1 (A), Egr2 (B) and Egr3 (C) expression levels were measured in dentate gyrus tissue in mice from the three genotypes in the basal condition (white bars) and 2 hours after MECS-induced seizure (black bars). (D) Sample Westerns blots in the control (CT) and MECS conditions. Values in each column represents densitometric quantification of expression of each Egr member normalised to basal level of expression in WT control mice. Actin was used as a control protein. Basal Egr1 and Egr2 expression was negligible in the dentate gyrus in all genotypes while Egr3 showed a much stronger constitutive expression (D). There was no difference in the basal levels of expression of the three Egr members in WT, HT and cKO mice. Egr1 was strongly and similarly induced after MECS in all genotypes (A,D). Egr2 was also strongly induced after MECS in WT mice, but not in cKO mice as expected $(\boldsymbol{B}, \mathbf{D})$. MECS-induced expression of Egr2 in HT mice was approximately half that observed in WT mice $(\boldsymbol{B}, \boldsymbol{D})$ and there was no induction of Egr3 following MECS in any of the genotypes (C,D). ${ }^{*} p<0.05$. 


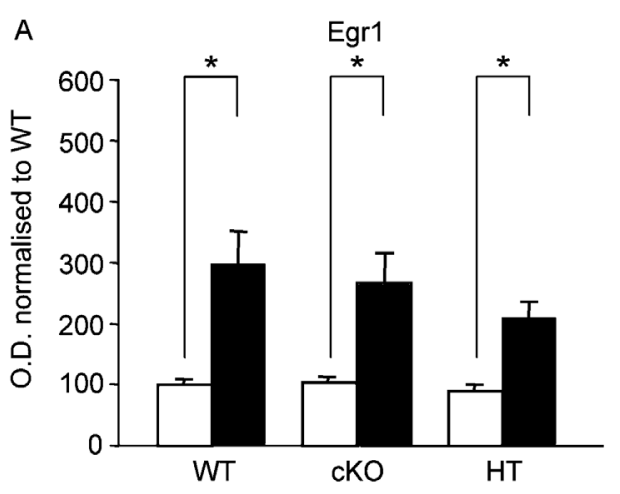

C

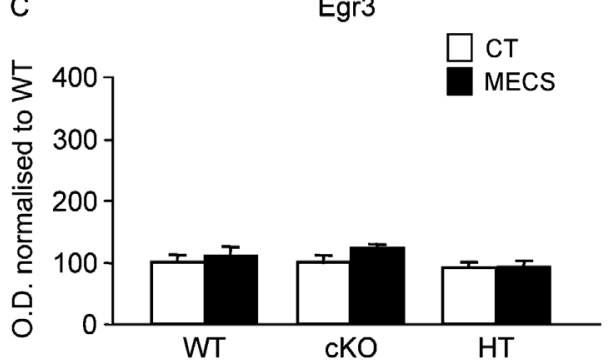

$\mathrm{B}$

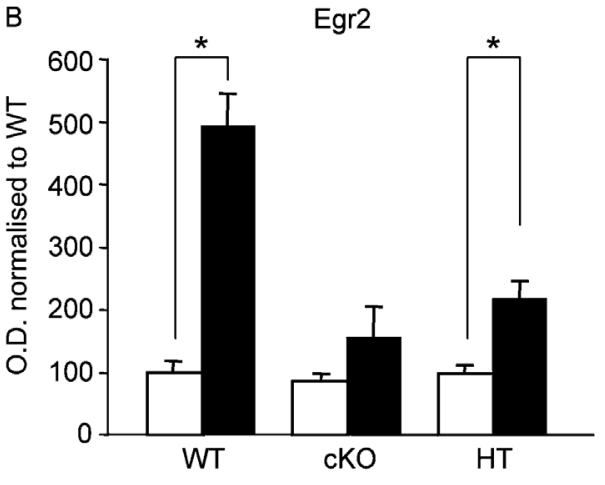

D

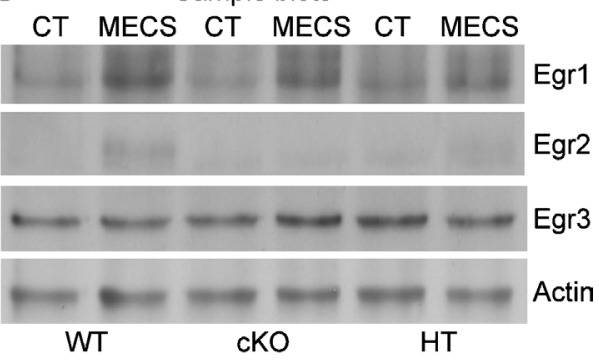

Figure 7. Basal and MECS-induced expression of Egr members in area CA1 of the hippocampus.Legend as in Figure 6 In CA1 of the hippocampus, Egr1 and Egr3 are constitutively expressed while Egr2 expression level was negligible (D). As in the dentate gyrus, each of the three Egr members had similar basal levels of expression in WT, HT and CKO mice (white bars). MECS (black bars) induced strong expression of Egr1 (A) and Egr2 (B), but not of Egr3 (C). There were comparable levels of MECS-induced expression of Egr1 in the three genotypes (A), whereas Egr2 induction was strong in WT mice, less in HT mice, and absent in cKO mice (B). ${ }^{*} p<0.05$.

$(t=0.4, p>0.05$; Figures 7B and 7D). These biochemical analyses, taken together, suggest that there is neither compensation, nor any linked detrimental effect on Egr1 and Egr3 in the dentate gyrus or CA1 in the absence of Egr2.

\section{DISCUSSION}

The Egr2/Krox20 gene, originally described by screening a cDNA library from serum-stimulated mouse NIH 3T3 cells (Chavrier et al., 1988), encodes a zinc-finger transcriptional regulator of the Egr family. Key roles for members of this family of transcription factors in several aspects of brain plasticity and cognitive functions are now well established for Egr1/ zif268 (Bozon et al., 2002; Bozon et al., 2003a; Bozon et al., 2003b; Jones et al., 2001; Lee et al., 2004; Malkani et al., 2004) and Egr3 (GallitanoMendel et al., 2007; Li et al., 2007). In humans, mutations in the Egr2 gene were found to be responsible for severe autosomal dominant and recessive forms of peripheral neuropathies (Bellone et al., 1999; Boerkoel et al., 2001; Pareyson et al., 2000; Timmerman et al., 1999; Warner et al., 1998; Yoshihara et al., 2001); however, MRI studies conducted in patients with a mutation in the Egr2 gene showed no evidence of structural or white matter abnormalities in the brain (Warner et al., 1998) and no obvious intellectual defect has been reported (Timmerman et al., 1999). In studying the role of Egr2 in conventional mutant mice, Egr2 was demonstrated to play a prominent role in regulation of peripheral nerve myelination (Topilko et al., 1994), hindbrain segmentation (SchneiderMaunoury et al., 1993; Swiatek and Gridley, 1993) and endochondreal bone formation (Levi et al., 1996). All these studies, however, examined the role of Egr2 during development whereas little is known about the functional role of the gene in the adult central nervous system. In this study, we generated a conditional mutant mouse (cKO) to inactivate Egr2 post-natally and specifically in forebrain neurons. These mice possess two different Egr2 alleles, null and floxed, respectively. In addition they carry a transgene in which the Cre recombinase is placed under the control of CaMKII regulatory sequences that are forebrain neuron-specific. In these mice Egr2 is therefore inactivated in forebrain neurons, whereas one allele is preserved in the rest of the body. Unlike conventional Egr2 knock-out mice, the cKO conditional mutants described here developed normally and their general behaviour was indistinguishable from that of their control littermates. Histological analysis revealed no gross abnormalities in the hippocampus or in the CNS in general. PCR and Western blotting established evidence for efficient forebrain deletion of Egr2. Thus, generation of this post-natal, forebrain-specific Egr2 deletion allowed us to circumvent perinatal lethality caused by other Egr2 functions (Decker et al., 2006; Schneider-Maunoury et al., 1993; Swiatek and Gridley, 1993; Topilko et al., 1994) and to explore the effect of Egr2 loss-of-function in learning and memory.

For the characterisation of Egr2 function in learning and memory we used a variety of behavioural tasks making use of single or repeated training, different types of reinforcement and the processing of spatial or non-spatial information. Our results provide evidence that none of the forms of learning examined are impaired in Egr2-deficient mice. Both cKO and HT transgenic mice demonstrated normal spatial learning and memory in the spatial navigation task, normal associative memory in a conditioned taste aversion task and normal fear learning and memory in a trace fear conditioning paradigm. Surprisingly, we also found that cKO transgenic mice had superior learning and memory abilities than control mice in two tasks, one involving implicit motor skill learning and the other measuring object recognition memory. cKO mice improved faster their motor skill performance in the accelerating rotarod test. They also demonstrated enhanced long-term recognition memory in the object recognition task. With the training protocol used for this task, control mice 
could form short-term, but not long-term recognition memory. In contrast, cKO mice were able to form a long-term recognition memory despite nonimproved short-term memory, suggesting facilitation of consolidation processes. In these two tasks, performance of heterozygous mice was in between that of homozygous and control mice, suggesting a gene-dosage effect.

Both $\mathrm{CKO}$ and HT mice had one non-forebrain restricted Egr2 null allele. Because Egr2 in required for normal hindbrain development and peripheral nerve myelination, and because non-cognitive factors may affect performance in tests of learning and memory, we evaluated the animal's sensory-motor abilities and emotional reactivity. We found cKO and HT mice had normal motor strength and coordination, normal performance in sensory-motor tests, swim speed in the water maze, locomotion during exploration of an open field and object exploration. We also examined anxiety-related behaviours and found no difference in the behaviour of the mutant mice in the elevated plus maze, in their swimming patterns in the water maze, exploratory activity in the open field, or in their reaction to novel objects. Egr2 mutant mice thus do not demonstrate any change in anxiety-related behaviours or adaptive reactions to the test environments. These results suggest that the absence of deficits in the learning tasks examined and the improvement of performance in motor skill learning and in recognition memory in Egr2-deficient mice cannot be accounted for by non-cognitive factors such as increased muscular strength, hyperactivity, enhanced motivation or tendency to explore novelty or reduced anxiety.

Clearly, the behavioural phenotype of cKO mice appears in sharp contrast to that of Egr1 and Egr3 mutant mice in similar tasks. The phenotype of Egr1 mutant mice is characterised by profound deficits restricted to long-term, but not short-term memory in several tasks (Bozon et al., 2002; Bozon et al., 2003b; Jones et al., 2001), including spatial learning, conditioned taste aversion and object recognition tasks for which we found no specific impairment when Egr2 is eliminated from forebrain neurons. Recent analyses of the behavioural phenotype of Egr3 mutant mice revealed a heightened reactivity to stressful stimuli and novel environments (Gallitano-Mendel et al., 2007) and a primary deficit in short-term memory in contextual fear conditioning and object recognition, with a consequential defect in long-term memory performance (Li et al., 2007). The present results thus reinforce the idea that Egr transcription factors do not share similar functions in learning and memory. Our Western blot analyses also suggest that the normal performance of Egr2deficient mice and the facilitation observed in certain tasks is not due to a compensatory overexpression, or a greater inducibility of the Egr family members known to be involved in learning and memory. We found no change in basal, constitutive levels of Egr1 or Egr3 protein expression, or in seizure-induced expression, in either area CA1 of the hippocampus or the dentate gyrus in $\mathrm{CKO}$ or HT mice, indicating that at least in hippocampal regions the absence of one or two Egr2 alleles is not associated with overexpression of these other Egr family members.

Like other Egr members, Egr2 can be induced in brain by various stimuli, including electroconvulsive shock inducing seizure activity (Bhat et al., 1992, this study), focal cerebral ischaemia (An et al., 1992), dopamine receptor activation and opiate withdrawal (Bhat et al., 1992) and in hippocampal neurons following kainic acid injection (Gass et al., 1994) or LTP-inducing stimuli (Williams et al., 1995), although Egr2 is less robustly induced and is not induced by weaker patterns of stimuli despite induction of long-lasting LTP along with Egr1 expression (Worley et al., 1993). As opposed to Egr1, however, which is rapidly induced in different brain structures after a variety of learning (Guzowski et al., 2001; Hall et al., 2001; Malkani and Rosen, 2000; Maviel et al., 2004; Okuno and Miyashita, 1996; Thomas et al., 2002), there is as yet no firm evidence for Egr2 induction after learning, at least in fear conditioning (Malkani and Rosen, 2000). Egr family members do not share similar cis-acting elements in their upstream regulatory regions and may therefore not respond to the same type of neuronal activation and intracellular signalling cascades (reviewed in Beckmann and Wilce, 1997; Herdegen and Leah,
1998). Thus, it is possible that Egr2, which seems expressed at lower levels than Egr1 and Egr3 in most brain regions as confirmed here in the dentate gyrus and area CA1 of the hippocampus, is not, or is less responsive to physiological neuronal activity during learning and is therefore dispensable for learning and memory. Overall, our results strengthen the idea that Egr members do not serve similar functions in the adult brain and indicate that Egr2, as opposed to Egr1 and Egr3, might not be crucial for cognitive functions.

The present findings also provide the first evidence that impaired forebrain Egr2 function may facilitate certain forms of learning and memory. This finding suggests that Egr2 can act as an inhibitory constrain for certain cognitive functions and imply that in certain circumstances Egr family members may have antagonistic functions in the adult brain. The mechanisms whereby Egr2 could have an antagonistic role towards brain function in the context of learning and memory are not known. There are several potential routes by which this could occur. One possibility is the control of different sets of downstream target genes. Despite recognising the same DNA binding sequence, Egr family members might regulate different genes because the recognition involves additional factors that interact specifically with non-conserved regions of the Egr proteins. The Egr family members might also regulate the same genes, but in opposite manners, due to the involvement in non-conserved regulatory regions. In addition, Egr2 might have a more direct antagonistic function towards the transcriptional activity of the other Egr members. In Schwann cells, for example, Egr1 and Egr2 are expressed in a successive and mutually exclusive manner during embryogenesis and examination of their role in myelination has suggested that they might compete and possibly repress each other (Topilko et al., 1997). Finally, Egr proteins also possess a domain for transcriptional repression mediated by the repressor proteins $\mathrm{Nab} 1$ and Nab2 that binds to and can repress Egr function (Russo et al., 1995; Svaren et al., 1996; Swirnoff et al., 1998). In this respect, it is interesting to note that a recent study identified multiple Egr binding sites on the promoter of Nab2 in a region critical for promoter activity, suggesting that Egr members are direct regulators of Nab2 (Kumbrink et al., 2005). Consistent with this, Egr2 was shown to positively regulate the expression of Nab1 and Nab2 in the developing hindbrain (MechtaGrigoriou et al., 2000, Desmazières, Charnay and Gilardi-Hebenstreit, unpublished data), and a gene expression profiling study in Schwann cells has identified Nab2 as a target of Egr2 (Nagarajan et al., 2001). Thus, it will be interesting in future studies to test the possibility that the absence of Egr2 resulted in a reduced expression of Nab proteins, thereby increasing or prolonging transcriptional activity of the remaining Egr family members as well as that of other transcription factors possessing Nab-mediated repression domains.

In summary, analysis of the behavioural phenotype of forebrainspecific Egr2-deficient mice revealed that this member of the Egr family of transcriptional regulators, as opposed to Egr1 and Egr3, is dispensable for several forms of learning and memory and can on the contrary act as a repressor for certain cognitive functions, suggesting that Egr members may have different, and in certain circumstances antagonistic functions in the adult brain.

\section{CONFLICT OF INTEREST STATEMENT}

We declare that the research was conducted in the absence of any commercial or financial relationships that could be construed as a potential conflict of interest.

\section{ACKNOWLEDGMENTS}

This work was supported by CNRS, INSERM, and by grants from the French Ministry of Research (ACl-NEURO-NIC-0027) to S.D. and P.C. and from EU Marie Curie Research Training Program (RTN-CT-2003-504231) to S.L. H.C. was supported by a fellowship from the French Ministry of Research. The authors are grateful to François Tronche for the gift of the 
CaMKII-Cre line, and to Claire Chevalier, Nathalie Samson, Pascale Veyrac and Sandra Vandergeenst for animal care. Our deepest thanks go to Emmanuel Taillebourg who was involved in the initiation of the generation of the conditional mutant, and to Sonia Garel for constant discussions and inputs throughout this work.

\section{REFERENCES}

Abraham, W. C., Dragunow, M., and Tate, W. P. (1991). The role of immediate early genes in the stabilization of long-term potentiation. Mol. Neurobiol. 5, 297-314.

Abraham, W. C. Mason, S. E., Demmer, J., Williams, J. M., Richardson, C. L., Tate, W. P., Lawlor, P. A., and Dragunow, M. (1993). Correlations between immediate early gene induction and the persistence of long-term potentiation. Neuroscience 56, 717-727.

An, G., Lin, T. N., Liu, J. S., and Hsu, C. Y. (1992). Induction of Krox-20 expression after focal cerebral ischemia. Biochem. Biophys. Res. Commun. 188, 1104-1110.

Beckmann, A. M., and Wilce, P. A. (1997). Egr transcription factors in the nervous system. Neurochem. Int. 31, 477-510.

Bellone, E., Di Maria, E., Soriani, S., Varese, A., Doria, L. L., Ajmar, F., and Mandich, P. (1999). A novel mutation (D305V) in the early growth response 2 gene is associated with severe Charcot-Marie-Tooth type 1 disease. Hum. Mutat. 14, 353-354.

Bhat, R. V., Worley, P. F., Cole, A. J., and Baraban, J. M. (1992). Activation of the zinc finger encoding gene krox-20 in adult rat brain: comparison with zif268. Mol. Brain Res. 13, 263-266.

Boerkoel, C. F., Takashima, H., Bacino, C. A., Daentl, D., and Lupski, J. R. (2001). EGR2 mutation R359W causes a spectrum of Dejerine-Sottas neuropathy. Neurogenetics 3, 153-157.

Bozon, B., Davis, S., and Laroche, S. (2002). Regulated transcription of the immediate early gene Zif268: mechanisms and gene dosage-dependent function in synaptic plasticity and memory formation. Hippocampus $12,570-577$.

Bozon, B., Davis, S., and Laroche, S. (2003a). A requirement for the immediate early gene zif268 in reconsolidation of recognition memory after retrieval. Neuron 40, 695701

Bozon, B., Kelly, A., Josselyn, S. A., Silva, A. J., Davis, S., and Laroche, S. (2003b). MAPK, CREB and zif268 are all required for the consolidation of recognition memory. Philos. Trans. R. Soc. B $358,805-814$.

Chavrier, P., Zerial, M., Lemaire, P., Almendral, J., Bravo, R., and Charnay, P. (1988). A gene encoding a protein with zinc fingers is activated during G0/G1 transition in cultured cells. EMBO J. 7, 29-35.

Chavrier, P., Vesque, C., Galliot, B. Vigneron, M., Dolle, P., Duboule, D., and Charnay, P. (1990). The segment-specific gene Krox-20 encodes a transcription factor with binding sites in the promoter region of the Hox-1.4 gene. EMBO J. 9, 1209-1218.

Davis, S., Bozon, B., and Laroche, S. (2003). How necessary is the activation of the immediate early gene zif268 in synaptic plasticity and learning ? Behav. Brain Res. 142, 17-30.

De, S., Shuler, C. F., and Turman, J. E., Jr., (2003). The ontogeny of Krox-20 expression in brainstem and cerebellar neurons. J. Chem. Neuroanat. 25, 213-226.

Decker, L., Desmarquet-Trin-Dinh, C., Taillebourg, E., Ghislain, J., Vallat, J. M., and Charnay, P. (2006). Peripheral myelin maintenance is a dynamic process requiring constant Krox20 expression. J. Neurosci. 26, 9771-9779.

Gallitano-Mendel, A., Izumi, Y., Tokuda, K., Zorumski, C. F., Howell, M. P., Muglia, L. J., Wozniak, D. F., and Milbrandt, J. (2007). The immediate early gene early growth response gene 3 mediates adaptation to stress and novelty. Neuroscience 148, 633643.

Gass, P., Herdegen, T., Bravo, R., and Kiessling, M. (1994). High induction threshold for transcription factor KROX-20 in the rat brain: partial co-expression with heat shock protein 70 following limbic seizures. Mol. Brain Res. 23, 292-298.

Giudicelli, F., Taillebourg, E., Charnay, P., and Gilardi-Hebenstreit, P. (2001). Krox-20 patterns the hindbrain through both cell-autonomous and non cell-autonomous mechanisms. Genes Dev. 15, 567-568.

Guzowski, J. F., Setlow, B., Wagner, E. K., and McGaugh, J. L. (2001). Experiencedependent gene expression in the rat hippocampus after spatial learning: a comparison of the immediate-early genes Arc, c-fos, and zif268. J. Neurosci. 21, 5089-5098.

Hall, J., Thomas, K. L., and Everitt, B. J. (2001). Cellular imaging of zif268 expression in the hippocampus and amygdala during contextual and cued fear memory retreival: selective activation of hippocampal CA1 neurons during the recall of contextual memories. J. Neurosci. 21, 2186-2193.

Herdegen, T., and Leah, J. D. (1998). Inducible and constitutive transcription factors in the mammalian nervous system: control of gene expression by Jun, Fos and Krox, and CREB/ATF proteins. Brain Res. Rev. 28, 370-490.

Herdegen, T., Kiessling, M., Bele, S., Bravo, R., Zimmermann, M., and Gass, P. (1993). The KROX-20 transcription factor in the rat central and peripheral nervous systems: novel expression pattern of an immediate early gene-encoding protein. Neuroscience 57, 41-52.

Jacquin, T. D., Borday, V., Schneider-Maunoury, S., Topilko, P., Ghilini, G., Kato, F. Charnay, P., and Champagnat, J. (1996). Reorganization of pontine rhythmogenic neuronal networks in Krox-20 knockout mice. Neuron 17, 747-758.

Jones, M. W., Errington, M. L., French, P. J., Fine, A., Bliss, T. V. P., Garel, S., Charnay, P., Bozon, B., Laroche, S., and Davis, S. (2001). A requirement for the immediate early gene Zif268 in the expression of late LTP and the consolidation of long-term memories. Nature Neurosci. 4, 289-296.
Knapska, E., and Kaczmarek, L. (2004). A gene for neuronal plasticity in the mammalian brain: Zif268/Egr-1/NGFI-A/Krox-24/TIS8/ZENK? Prog. Neurobiol. 74, 183-211.

Kumbrink, J., Gerlinger, M., and Johnson, J. P. (2005). Egr-1 induces the expression of its corepressor nab2 by activation of the nab2 promoter thereby establishing a negative feedback loop. J. Biol. Chem. 280, 42785-42793.

Lee, J. L., Everitt, B. J., and Thomas, K. L. (2004). Independent cellular processes for hippocampal memory consolidation and reconsolidation. Science 304, 839-843.

Lemaire, P., Vesque, C., Schmitt, J., Stunnenberg, H., Frank, R., and Charnay, P. (1990). The serum-inducible mouse gene Krox-24 encodes a sequence-specific transcriptional activator. Mol. Cell Biol. 10, 3456-3467.

Levi, G., Topilko, P., Schneider-Maunoury, S., Lasagna, M., Mantero, S., Cancedda, R., and Charnay, P. (1996). Defective bone formation in Krox-20 mutant mice. Development 122, 113-120.

Li, L., Yun, S. H., Keblesh, J., Trommer, B. L., Xiong, H., Radulovic, J., and Tourtellotte, W. G. (2007). Egr3, a synaptic activity regulated transcription factor that is essential for learning and memory. Mol. Cell Neurosci. 35, 76-88.

Mack, K., Day, M., Milbrandt, J., and Gottlieb, D. I. (1990). Localization of the NGF1-A protein in the rat brain. Mol. Brain Res. 8, 177-180.

Mack, K. J., Cortner, J., Mack, P., and Farnham, P. J. (1992). Krox-20 messenger RNA and protein expression in the adult central nervous system. Mol. Brain Res. 14, 117123

Malkani, S., and Rosen, J. B. (2000). Specific induction of early growth response gene 1 in the lateral nucleus of the amygdalal following contextual fear conditioning in rats. Neuroscience 97, 693-702.

Malkani, S., Wallace, K. J., Donley, M. P., and Rosen, J. B. (2004). An egr-1 (zif268) antisense oligodeoxynucleotide infused into the amygdala disrupts fear conditioning. Learn. Memory 11, 617-624.

Mantamadiotis, T., Lemberger, T., Bleckmann, S. C., Kern, H., Kretz, 0., Martin Villalba, A., Tronche, F., Kellendonk, C., Gau, D., Kapfhammer, J., Otto, C., Schmid, W., and Schutz, G. (2002). Disruption of CREB function in brain leads to neurodegeneration. Nat. Genet. 31, 47-54.

Maviel, T., Durkin, T. P., Menzaghi, F., and Bontempi, B. (2004). Sites of neocortical reorganization critical for remote spatial memory. Science 305, 96-99.

Mechta-Grigoriou, F., Garel, S., and Charnay, P. (2000). Nab proteins mediate a negative feedback loop controlling Krox-20 activity in the developing hindbrain. Development 127, 119-128.

Nagarajan, R., Svaren, J., Le, N., Araki, T., Watson, M., and Milbrandt, J. (2001). EGR2 mutations in inherited neuropathies dominant-negatively inhibit myelin gene expression. Neuron 30, 355-368.

O'Donovan, K. J., Wilkens, E. P., and Baraban, J. M. (1998). Sequential expression of Egr1 and Egr-3 in hippocampal granule cells following electroconvulsive stimulation. J. Neurochem. 70, 1241-1248.

O'Donovan, K. J., Tourtellotte, W. G., Milbrandt, J., and Baraban, J. M. (1999). The EGR family of transcription-regulatory factors: progress at the interface of molecular and systems neuronscience. Trends Neurosci. 22, 167-173.

Okuno, H., and Miyashita, Y. (1996). Expression of the transcription factor Zif268 in the temoral cortex of monkeys during visual paired associate learning. Eur. J. Neurosci. 8, 2118-2128.

Pareyson, D., Taroni, F., Botti, S., Morbin, M., Baratta, S., Lauria, G., Ciano, C., and Sghirlanzoni, A. (2000). Cranial nerve involvement in CMT disease type 1 due to early growth response 2 gene mutation. Neurology 54, 1696-1698.

Poirier, R., Jacquot, S., Vaillend, C., Soutthiphong, A. A., Libbey, M., Davis, S., Laroche, S., Hanauer, A., Welzl, H., Lipp, H. P., and Wolfer, D. P. (2007). Deletion of the CoffinLowry syndrome gene Rsk2 in mice is associated with impaired spatial learning and reduced control of exploratory behavior. Behav. Genet. 37, 31-50.

Richardson, C. L., Tate, W. P. Mason, S. E., Lawlor, P. A., Dragunow, M., and Abraham, W. C. (1992). Correlation between the induction of an immediate early gene, zif/268, and long-term potentiation in the dentate gyrus. Brain Res. 580, 147-154.

Russo, M. W., Sevetson, B. R., and Milbrandt, J. (1995). Identification of NAB1, repressor of NGFI-A- and Krox20-mediated transcription. Proc. Natl. Acad. Sci. USA $92,6873-6877$.

Schneider-Maunoury, S., Topilko, P., Seitandou, T., Levi, G., Cohen-Tannoudji, M. Pournin, S., Babinet, C., and Charnay, P. (1993). Disruption of Krox-20 results in alteration of rhombomeres 3 and 5 in the developing hindbrain. Cell 75, 11991214.

Svaren, J., Sevetson, B. R. Apel, E. D., Zimonjic, D. B. Popescu, N. C., and Milbrandt, J. (1996). NAB2, a corepressor of NGFI-A (Egr-1) and Krox20, is induced by proliferative and differentiative stimuli. Mol. Cell. Biol. 16, 3545-3553.

Swiatek, P. J., and Gridley, T. (1993). Perinatal lethality and defects in hindbrain development in mice homozygous for a targeted mutation of the zinc finger gene Krox-20. Genes Dev. 7, 2071-2084.

Swirnoff, A. H., and Milbrandt, J. (1995). DNA-binding specificity of NGF1-A and related zinc finger transcription factors. Mol. Cell Biol. 15, 2275-2287.

Swirnoff, A. H., Apel, E. D., Svaren, J., Sevetson, B. R., Zimonjic, D. B., Popescu, N. C. and Milbrandt, J. (1998). Nab1, a corepressor of NGFI-A (Egr-1), contains an active transcriptional repression domain. Mol. Cell. Biol. 18, 512-524.

Taillebourg, E., Buart, S., and Charnay, P. (2002). A conditional, floxed allele of the Krox20 gene. Genesis 32, 112-113.

Thomas, K. L., Hall, J., and Everitt, B. J. (2002). Cellular imaging with zif268 expression in the rat nucleus accumbens and the frontal cortex further dissociated the neural pathways activated following the retrieval of contextual and cued memory. Eur. J. Neurosci. 16, 1789-1996.

Timmerman, V., De Jonghe, P., Ceuterick, C., De Vriendt, E., Lofgren, A., Nelis, E Warner, L. E., Lupski, J. R., Martin, J. J., and Van Broeckhoven, C. (1999). Novel 
missense mutation in the early growth response 2 gene associated with DejerineSottas syndrome phenotype. Neurology 52, 1827-1832.

Topilko, P., Schneider-Maunoury, S., Levi, G., Baron-Van Evercooren, A., Chennoufi, A. B., Seitanidou, T., Babinet, C., and Charnay, P. (1994). Krox-20 controls myelination in the peripheral nervous system. Nature $371,796-799$.

Topilko, P., Levi, G., Merlo, G., Mantero, S., Desmarquet, C., Mancardi, G., and Charnay, P. (1997). Differential regulation of the zinc finger genes Krox-20 and Krox-24 (Egr-1) suggests antagonistic roles in Schwann cells. J. Neurosci. Res. 50, 702-712.

Vaillend, C., Billard, J. M., and Laroche, S. (2004). Impaired long-term spatial and recognition memory and enhanced CA1 hippocampal LTP in the dystrophin-deficient Dmdmdx mouse. Neurobiol. Dis. 17, 10-20.

Warner, L. E., Mancias, P., Butler, I. J., McDonald, C. M., Keppen, L., Koob, K. G., and Lupski, J. R. (1998). Mutations in the early growth response 2 (EGR2) gene are associated with hereditary myelinopathies. Nat. Genet. 18, 382-384.
Williams, J., Dragunow, M., Lawlor, P. A., Mason, S. E., Abraham, W. C., Leah, J., Bravo, R., Demmer, J., and Tate, W. (1995). Krox20 may play a key role in the stabilisation of long-term potentiation. Mol. Brain Res. 28, 87-93.

Worley, P. F., Bhat, R. V., Baraban, J. M., Erickson, C. A., McNaughton, B. L., and Barnes, C. A. (1993). Thresholds of synaptic activation of transcription factors in hippocampus: correlation with long-term enhancement. J. Neurosci. 13, 4776-4786.

Yamagata, K., Kaufmann, W. E., Lanahan, A., Papapavlous, M., Barnes, C. A., Andreasson, K. I., and Worley, P. F. (1994). Egr3/Pilot, a zinc finger transcription factor, is rapidly regulated by activity in brain neurons and colocalize with Egr-1/ zif268. Learn. Memory 1, 140-152.

Yoshihara, T., Kanda, F., Yamamoto, M., Ishihara, H., Misu, K., Hattori, N., Chihara, K. and Sobue, G. (2001). A novel missense mutation in the early growth response 2 gene associated with late-onset Charcot-Marie-Tooth disease type 1. J. Neurol. Sci. 184, 149-153. 